\title{
Overexpression of squamous cell carcinoma antigen variants in hepatocellular carcinoma
}

\author{
P Pontisso*, , F Calabrese ${ }^{2}$, L Benvegnù', M Lise ${ }^{3}$, C Belluco ${ }^{3}$, MG Ruvoletto', S De Falco ${ }^{4}$, M Marino ${ }^{5}$, \\ M Valente ${ }^{2}$, D Nitti ${ }^{3}$, A Gatta' and G Fassina ${ }^{5}$
}

'Department of Clinical and Experimental Medicine, Via Giustiniani, 2 35 I23, Padova, Italy; ${ }^{2}$ Department of Pathology, University of Padova, via Gabelli 61, 35 I 2 I, Padova, Italy; ${ }^{3}$ Department of Oncological and Surgical Sciences, University of Padova, via Giustiniani, 235 I 23, Padova, Italy; ${ }^{4}$ CNR Napoli, via Castellino III, 80100 Napoli, Italy; ${ }^{5}$ Xeptagen S.p.A, via Olivetti, I, 80078 Pozzuoli (NA), Italy

\begin{abstract}
Pathogenetic mechanisms of hepatocellular carcinoma (HCC) are still unclear and new tools for diagnostic and therapeutic purposes are ongoing. We have assessed whether squamous cell carcinoma antigen (SCCA), a serpin overexpressed in neoplastic cells of epithelial origin, is also expressed in liver cancer. Squamous cell carcinoma antigen was evaluated by immunohistochemistry in 65 HCCs of different aetiology and in 20 normal livers. Proliferative activity was assessed using MIB-I antibody. In I 8 surgical samples, tumour and nontumour liver tissue was available for SCCA cDNA amplification and sequencing. Squamous cell carcinoma antigen was detected in 55 out of 65 (85\%) tumour specimens, but in none of the 20 controls. In the majority of the cases, the positive signal was found in the cytoplasm of more than $50 \%$ of the hepatocytes. Low or undetectable SCCA (score $\leqslant 1$ ) was associated to lower MIB-I labelling index, compared to cases with SCCA score $\geqslant 2$ (mean \pm s.d.: $2 \% \pm 2.4$ vs $7.5 \% \pm 10.3, P<0.05$ ). Squamous cell carcinoma antigen mRNA could be directly sequenced in 14 out of 18 liver tumours but in none of the corresponding nontumour samples. From sequence alignment, a novel SCCAI variant $\left(\mathrm{G}_{35}\right.$ I to $\left.A\right)$ was identified in five cases, while SCCAI was revealed in six cases and SCCA2 in three cases. In conclusion, SCCA variants are overexpressed in HCC, independently of tumour aetiology. A novel SCCAI variant has been identified in one third of liver tumours.

British Journal of Cancer (2004) 90, 833-837. doi:I0.1038/sj.bjc.660I543 www.bjcancer.com
\end{abstract}

(c) 2004 Cancer Research UK

Keywords: serpin variants; HCC; proliferative activity; molecular biology

Hepatocellular carcinoma (HCC) is one of the most important sanitary problems over the world for its high prevalence and for its poor prognosis. More than 250000 new cases per year are diagnosed and mean 5-year survival is lower than 5\% (El-Serag and Mason, 1999). Several factors have been involved in the development of liver cancer, some of them differing in various geographic areas and explaining, at least in part, distinct geographical incidence (Bruix et al, 2001). The most powerful risk factor is the presence of liver cirrhosis. Among cirrhotic Caucasian patients, chronic viral infection by HBV and HCV are the most biologically relevant causes leading to this clinical condition (Benvegnù et al, 1994). However, pathogenetic mechanisms of neoplastic transformation are still unclear; several growth factors and tumour suppressor genes (Collier et al, 1993; Naka et al, 1998; Abou-Shady et al, 1999) have been involved but insufficient data have been generated to date. cDNA microarray analyses for gene expression profiling and potential identification of target genes for diagnostic or therapeutic purposes are ongoing (Shirota et al, 2001; Takeo et al, 2001; Xu et al, 2001).

\footnotetext{
* Correspondence: P Pontisso, Clinica Medica 5, Department of Clinical and Experimental Medicine, Via Giustiniani, 2 35।23, Padova, Italy; E-mail: patrizia@unipd.it

Received 4 July 2003; revised 22 October 2003; accepted 5 November 2003
}

Squamous cell carcinoma antigen is a serine protease inhibitor physiologically found in the spinous and granular layers of normal squamous epithelium, but typically expressed by neoplastic cells of epithelial origin (Kato, 1996). Recent studies indicate that both SCCA1 and SCCA2, the two isoforms so far identified (Schneider et al, 1995), protect neoplastic cells from apoptotic death induced by several kinds of stimuli, and in vivo experiments demonstrate that SCCA1 can promote tumour growth (Suminami et al, 2000, 2001). Little is known on the behaviour of this serpin in different clinical settings; in particular, no information is available on its expression in hepatocarcinoma. In the present study, we analysed the expression of SCCA in a large series of HCCs of different aetiology, using a novel antibody raised against SCCA variants and cellular transcripts were then characterised by direct sequencing.

\section{MATERIALS AND METHODS}

\section{Patients}

The 65 HCC patients included in the study had a median age of 65 years (range 23-76 years), with a male/female ratio of 2:1. In total, 37 patients were anti-HCV positive, eight were HBsAg positive, six were coinfected by HBV and HCV, eight admitted alcohol abuse, while for the remaining six patients no risk factors were identified. Liver function tests and AFP were available in all cases, as required for clinical management of the patients. Liver specimens, achieved 
for diagnostic purposes, were obtained by ultrasound-guided fineneedle aspiration of hepatic nodules in 47 patients with cirrhosis, while in the remaining 18 patients, including 12 cases with cirrhosis and six without cirrhosis, specimens of tumour and nontumour liver samples were collected at the time of surgical resection. Formalin-fixed and paraffin-embedded sections were available in all cases, while part of the surgical samples was snap frozen in liquid nitrogen and stored at $-80^{\circ} \mathrm{C}$ for further analysis. Control liver biopsies were obtained from 20 patients who underwent cholecystectomy or liver biopsy for the staging of mediastinal or laterocervical Hodgkin's disease (Calabrese et al, 2000).

\section{Histological evaluation}

Paraffin sections were analysed for the presence of SCCA and regeneration activity by immunohistochemistry. For SCCA detection, a novel polyclonal rabbit antibody (Hepa-Ab, Xeptagen, Italy) raised against recombinant SCCA1 and affinity purified on a Sepharose-SCCA1 column was used. Epitope mapping studies with SCCA1 fragments obtained by SCCA1 enzymatic digestion or by chemical synthesis indicated that the affinity-purified polyclonal antibody recognises several epitopes located in the N-terminal, Cterminal as well as in the central portion of SCCA1, as determined by enzyme-linked immunosorbent assay (ELISA) and Western blot. Hepa-Ab was used at a concentration of $4 \mu \mathrm{g} \mathrm{ml}^{-1}$, while antiKi67 (MIB-1, Immunotech, Marseille, France) monoclonal antibody was used at 1:50 dilution. Sections were incubated with primary antibodies for $30 \mathrm{~min}$, after blocking endogenous peroxidase activity with $3 \%$ hydrogen peroxide, heating the slides in $10 \mathrm{~mm}$ sodium citrate in a microwave oven and blocking nonspecific protein binding in normal goat serum. Biotinylated goat anti-rabbit or horse anti-mouse (Dako, Copenhagen, Denmark) was then added for $30 \mathrm{~min}$. Samples were incubated with avidin-biotin-peroxidase and stained with a mixture of $3,3^{\prime}$ diamino-benzidine tetrahydrochloride (Dako) and hydrogen peroxide. For all experiments of immunohistochemistry, as negative control, sections were incubated with the omission of primary antibody, substituted by diluent or by the appropriate nonimmune IgG in each case. Antibody specificity was confirmed using human skin specimens for SCCA and colonic cancer specimens for Ki67, as positive controls.

The percentage of stained cells in each specimen was scored on a scale of $0-3$, in which 0 denoted negative staining, score 1 positivity in $1-30 \%$ of hepatocytes, score 2 positivity in $31-50 \%$ and score 3 in more than $50 \%$. The distribution of immunoreactivity was noted and classified as diffuse, clustered or scattered. In all cases, SCCA semiquantitative immunoreactivity was independently evaluated by two pathologists, experts in the field. Intra and interobserver differences were less than 5\% and discordant cases were re-evaluated simultaneously by two observers.

For tumour liver specimens obtained by resection, MIB-1 immunostaining was randomly evaluated counting at least 1000 nuclei, while in liver samples obtained by needle aspiration all the cells were counted (maximum 500 cells). The percentage of positive nuclei was expressed as MIB-1 labelling index (MIB-1-LI).

In all immunohistochemical analysis, necrotic areas and edges of tissue sections were not included in the counting to avoid possible immunohistochemical false positivity.

\section{Virological assessment}

Anti-HCV antibody positivity was determined by commercially available ELISA and confirmed by recombinant immunoblot assay version 2 or 3 (Ortho Diagnostics, Raritan, NJ, USA). HBsAg, $\mathrm{HBeAg}$ and the presence of serum anti-HBc, anti-HBe and antiHBs antibodies were evaluated by ELISA using commercially available kits (Abbott Diagnostics, North Chicago, IL, USA). HCV genotype was determined by the InnoLipa test (Innogenetics, Gent, Belgium) after reverse transcription (RT) - PCR amplification. In order to detect possible occult $\mathrm{HBV}$ infection, aliquots of liver HBV DNA were assessed in 17 out of $18 \mathrm{HBsAg-negative} \mathrm{surgical}$ samples by nested PCR using primers derived from the core and the S regions of viral DNA (Cacciola et al, 1999).

\section{Characterisation of SCCA transcripts}

cDNAs of the SCCA-related variants were obtained by RTheminested PCR starting from total RNA extracted by single-step guanidinium method (Chomczynsky and Sacchi, 1987) from surgically obtained frozen tumour and nontumour liver samples. Samples containing $1 \mu \mathrm{g}$ RNA were treated with $1 \mathrm{U}^{-1} \mathrm{l}^{-1}$ of DNAse $\mathrm{I}$ in reaction buffer (200 mM Tris- $\mathrm{HCl}(\mathrm{pH} 8.4), 20 \mathrm{mM} \mathrm{MgCl}_{2}$, $500 \mathrm{~mm} \mathrm{HCl}$ ), followed by the addition of $25 \mathrm{~mm}$ EDTA at $65^{\circ} \mathrm{C}$ for 10 min to block the reaction. To generate cDNAs of SCCA variants, $\mathrm{RT}$ and amplification were carried out using primers located in conserved regions of SCCA1 and SCCA2. Briefly, RT was carried out using 2 pmol of the antisense primer at position 1416-1386 of SCCA sequence (Suminami et al, 1991) and $1 \mu \mathrm{l}$ of reverse transcriptase (Superscript II, GIBCO BRL). For the first step of cDNA amplification, $5 \mathrm{U} \mathrm{ml}^{-1}$ of Taq polymerase (Experteam, Italy) and the following primers were used: sense (CAT GAA TTC ACT CAG TGA AGC CAA C), antisense (GCA ATC AGT TTA CCA GAA CAT CTG CAG). After 40 cycles at $94^{\circ} \mathrm{C}$ for $1 \mathrm{~min}, 60^{\circ} \mathrm{C}$ for $30 \mathrm{~s}, 72^{\circ} \mathrm{C}$ for $1 \mathrm{~min}$, heminested PCR was carried out for additional 40 cycles in the same conditions using the sense primer described above and the antisense primer (GAC TGA ATT CAA ATC CAC TGA TGC). Actin mRNA was used as control of extracted RNA and RT - PCR was assessed using the following primers: sense (GTG GGG CGC CCC AGG CAC CA), antisense (CTC CTT AAT GTC ACG CAC GAT TTC). cDNA amplification was carried out for 35 cycles at $94^{\circ} \mathrm{C}$ for $1 \mathrm{~min}, 55^{\circ} \mathrm{C}$ for $1 \mathrm{~min}$ and $72^{\circ} \mathrm{C}$ for $2 \mathrm{~min}$.

Samples positive for the expected $945 \mathrm{bp}$ band obtained with the SCCA-derived primers were directly sequenced in both strands using an ABI PRISM BigDay terminator ready reaction kit following the manufacturer's instructions (Perkin Elmer Cetus, Emeryville, CA, USA). Electrophoresis of the sequencing products was performed by an ABI 377 automated DNA sequencer (Perkin Elmer Cetus) according to the manufacturer.

\section{Statistical analysis}

The Kruskal-Wallis ANOVA median test, Spearman rank correlation, $\chi^{2}$ and Fisher exact test were used for the analysis of the results.

\section{RESULTS}

\section{Immunohistochemistry}

Squamous cell carcinoma antigen was detected by immunohistochemistry in 55 out of $65(85 \%)$ tumour specimens (18 out of 18 surgical specimens and 37 out of 47 fine-needle liver biopsies), but in none of the 20 surgically obtained normal human livers (Figure 1). In the majority of the cases, the positive signal was clearly detectable with score 1 in $15 \%$ of the cases, score 2 in $29 \%$ and score 3 in the remaining $56 \%$ of the patients. The same extent of immunoreactivity was observed in liver tumours expressing SCCA1, SCCA2 or SCCA-PD variants as detected by direct sequencing (see below). In all cases, the serpin was detected in the cell cytoplasm, with a prevalent diffuse pattern. In poorly differentiated tumours, a typical clustered, coarse pattern was observed (Figure 2). No correlation with the diameter, histotype or grading of the tumour was observed. When surgical liver specimens were considered, patients with cirrhosis showed a 


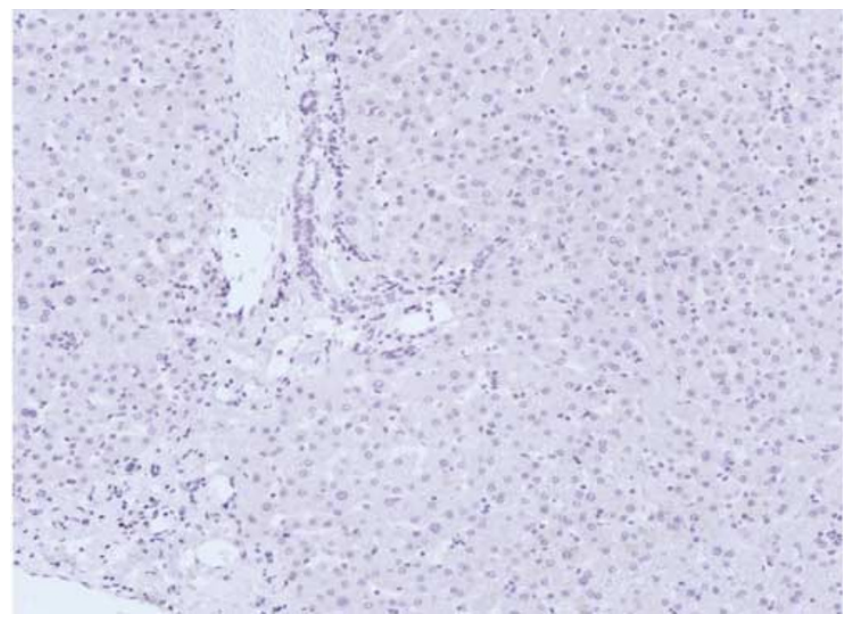

Figure I Negative liver staining for SCCA variants by immunohistochemistry in normal human liver (staging liver biopsy from a patient with mediastinal Hodgkin's disease). Original magnification: $\times 20$.

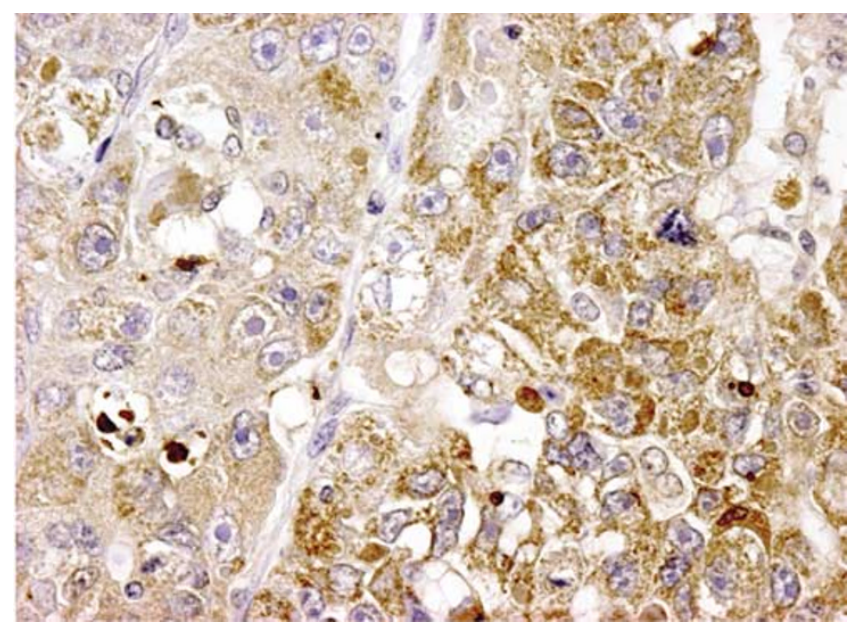

Figure 2 Immunohistochemistry for SCCA variants (score 3) in poorly differentiated HCC (giant cell form): most of the tumour cells show typical clustered, coarse, brown granules. Original magnification: $\times 572$.

higher score, compared to cases without cirrhosis (mean score \pm s.d.: $3 \pm 0.7$ vs $2 \pm 0.4, P<0.05)$.

To correlate the presence of SCCA with liver regeneration activity, consecutive slices of each tumour were stained with the Ki-67 equivalent, MIB-1 antibody, which identifies cycling cells in formalin-fixed tissue samples (Cattoretti et al, 1992).

Patients with SCCA score $\leqslant 1$ showed values of MIB-1-LI significantly lower than those obtained in patients with serpin score $\geqslant 2$ (mean + s.d.: $2 \% \pm 2.4$ ([range $0.1-6.3 \%)]$ vs $7.5 \% \pm 10.3$ ([range $0.2-48 \%)], P<0.05$ ), as shown in Figure 3 .

\section{Squamous cell carcinoma antigen transcripts analysis}

Squamous cell carcinoma antigen mRNAs were detectable by heminested PCR in 14 out of 18 tumour samples, generating a single band at the expected size of $945 \mathrm{bp}$. None of the corresponding nontumour liver tissues showed detectable levels of the serpin in the same experimental conditions (Figure 4A). The sensitivity of this molecular approach was lower than that of immunohistochemistry for SCCA, where all tumour samples were positive for the serpin. The nucleotide sequence alignment of the cDNA obtained by direct sequencing from the 14 tumours showed

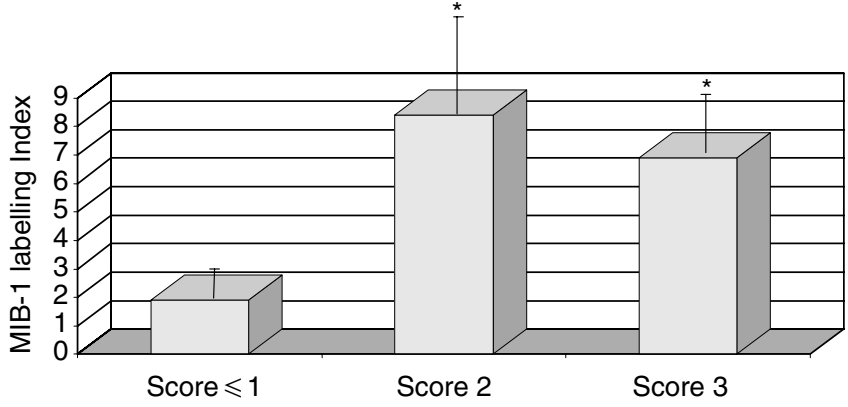

Figure 3 Proliferative activity expressed as MIB-I-labelling Index in HCCs with different SCCA scores. Results are expressed as percent mean + s.e. ${ }^{*} P<0.05$ vs score $\leqslant$ I group, Student's paired $t$-test.

that the major SCCA sequence had complete homology with SCCA1 in six cases and with SCCA2 in three cases. In five additional cases, a novel variant, presenting a $\mathrm{G}_{351}$ to $A$ mutation, in the reactive centre loop of the protein, was identified (Figure 4B) and termed SCCA-PD (GenBank accession number: AY190327).

\section{Correlation with clinical and virological parameters}

The immunoreactivity for SCCA variants in liver tumours did not show any relation with clinical and biochemical parameters, including age, sex, transaminase or AFP levels. Aetiology of HCC did not correlate with serpin expression, the mean \pm s.d. score being $2.1 \pm 1.1$ in HCV-infected patients, $2.1 \pm 1.7$ in HBsAgpositive patients, $2.2 \pm 0.4$ in patients with $\mathrm{HBV}$ and $\mathrm{HCV}$ coinfection, $2.1 \pm 1.6$ in patients with alcohol abuse and $2.0 \pm 0.5$ in cases without overt risk factors. Occult positivity for HBV was detected in five out of 17 surgical samples obtained from HBsAgnegative patients, independently of anti-HBc or anti-HBs positivity. In HCV-positive patients, no correlation with the infecting genotype was observed.

\section{DISCUSSION}

In view of its prevalence and poor prognosis, HCC is a main concern. This is the first report of an high expression of SCCA in human liver cancer, detected in all surgical tumours and in $79 \%$ of the samples obtained by fine-needle aspiration, confirming a lower sensitivity of the single fine-needle procedure (Borzio et al, 1994). The majority of HCCs displayed the serpin at cytoplasmic level, while its reactivity was not detectable in normal human livers. The presence and extent of immunoreactivity, as detected using a novel anti-SCCA antibody, was not correlated with aetiologic risk factors, suggesting that overexpression of this protein is involved in pathologic stages, beyond promotion of cell transformation.

The role of serpins in neoplastic cells has been focused in several studies and recent reports indicate that SCCA expression makes cancer cells resistant to several killing mechanisms by inhibition of apoptosis, involving caspase-3 activity and/or upstream proteases (Suminami et al, 2000). So far, two isoforms of SCCA (SCCA1 and SCCA2) deriving from two highly homologous tandemly arrayed genes and their promoter regions have been identified on chromosome 18q21.3 (Schneider et al, 1995; Sakaguchi et al, 1999; Hamada et al, 2001). In this study, direct sequencing was used to characterise the expression of the major species of SCCA variants in individual tumours and a new variant has been identified in about one third of the cases, which is $99 \%$ identical to SCCA1, but presents a $\mathrm{G}_{351}$ to $A$ mutation in the reactive centre of the protein. Since the mechanism of protease inhibition by serpins involves a profound change in conformation, initiated by 
A

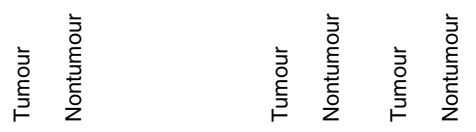

Patient 1 PC NC

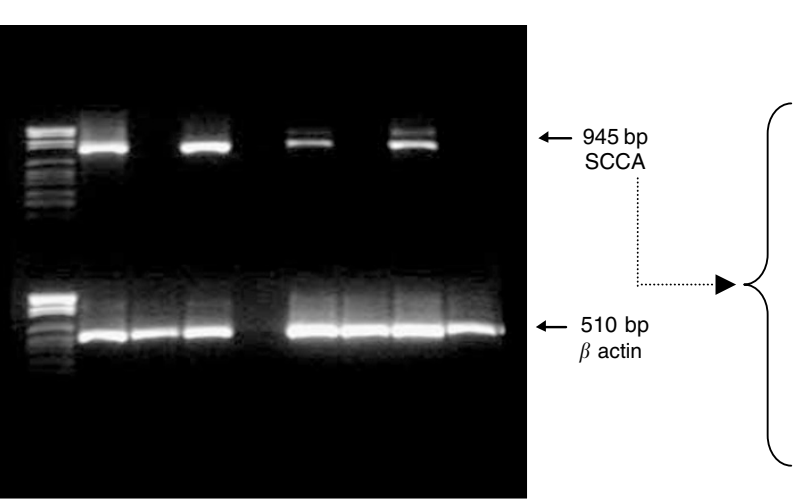

B

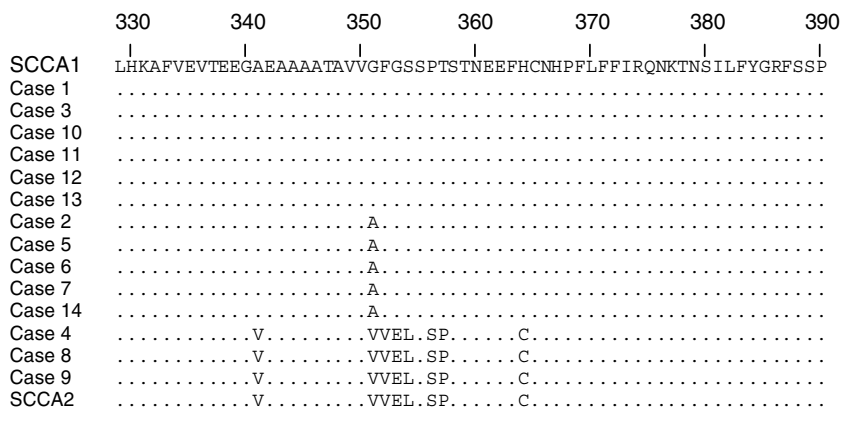

Figure 4 (A) Example of PCR amplification of SCCA cDNA by heminested PCR in tumour and nontumour liver tissue, surgically obtained from the same patient. Parallel amplification of $\beta$ actin cDNA is used as control of cellular mRNA. PC $=$ positive control; NC= negative control. (B) Sequence alignment of SCCA amino-acid sequences obtained from direct sequencing of cDNA of I4 HCCs. The sequence at the top is SCCAI and the sequence at the bottom is SCCA2 (Suminami et al, 1991). Amino-acid changes differing from SCCAI reference sequence are reported. Cases 2 , 5, 6, 7, I4 show the G351 $\rightarrow$ A mutation (SCCA-PD)

interaction of the protease with the reactive centre of the serpin (Huntington et al, 2000), the specific amino-acid change detected in the reactive centre of SCCA-PD might confer a different biological behaviour to the serpin and enzymatic activity of this new variant is currently under investigation. Mutations affecting this region may indeed result in inhibition of different classes of proteinases, as shown for SCCA1 and SCCA2 (Kato, 1996) or in a loss or change of function, as described in several human diseases affecting different members of the ovalbumin family of serpins, including emphysema and cirrhosis, haemorragic diseases, thrombosis and familial angioedema (Carrell and Lomas, 2002).

\section{REFERENCES}

Abou-Shady M, Baer HU, Friess H, Berberat P, Zimmermann A, Graber H, Gold LI, Korc M, Buchler MW (1999) Transforming growth factor beta and their signalling receptors in human hepatocellular carcinoma. Am J Surg 177: 209-215

Benvegnù L, Fattovich G, Noventa F, Tremolada F, Chemello L, Cecchetto A, Alberti A (1994) Concurrent hepatitis B and C virus infection and risk of hepatocellular carcinoma in cirrhosis. Cancer 74: 2442-2448

Borzio M, Borzio F, Macchi R, Croce AM, Bruno S, Ferrari A, Servida E (1994) The evaluation of fine-needle procedures for the diagnosis of focal liver lesions in cirrhosis. J Hepatol 20: 117-121

Bruix J, Sherman M, Llovet JM, Beaugrand M, Lencioni R, Burroughs AK, Christensen E, Pagliaro L, Colombo M, Rodés J, for the EASL Panel of Experts on HCC (2001) Clinical management of hepatocellular carcinoma. Conclusions of the Barcelona-2000 EASL Conference. J Hepatol 35: $421-430$

Cacciola I, Pollicino T, Squadrito G, Cerenzia G, Orlando ME, Raimondo G (1999) Occult hepatitis B virus infection in patients with chronic hepatitis C liver disease. $N$ Engl J Med 341: $22-26$

Calabrese F, Pontisso P, Pettenazzo E, Benvegnù L, Vario A, Chemello L, Alberti A, Valente ML (2000) Liver cell apoptosis in chronic hepatitis C correlates with histological but not biochemical activity or serum HCV RNA levels. Hepatology 31: 1153-1159

Carrell RW, Lomas DA (2002) Alpha1-antitripsyn deficiency. A model for conformational diseases. $N$ Engl J Med 346: $45-53$

Cattoretti G, Becker M, Key G, Duchrow M, Schluter C, Galle J, Gerdes J (1992) Monoclonal antibodies against recombinant parts of Ki-67
The SCCA-PD variant was detected in one third of the cases and the limited number of patients did not allow any correlation with clinical or morphological parameters. Further studies are required to assess whether tumour behaviour and clinical outcome of patients with HCC are influenced by the extent and/or type of SCCA expression in individual tumours.

\section{ACKNOWLEDGEMENTS}

This study was supported in part by a grant from the Italian Ministry of Health (RF 01/119) and by a grant from the Italian Ministry of Innovation, University and Research (11467). antigen (MIB and MIB3) detect proliferating cells in microwave processed formalin-fixed paraffin sections. J Pathol 168: 357-363

Chomczynsky P, Sacchi N (1987) Single-step method of RNA isolation by acid guanidinium thiocyanate-phenol-chloroform extraction. Anal Biochem 162: 156-159

Collier JD, Guo K, Gullick WJ, Bassendine MF, Burt AD (1993) Expression of transforming growth factor alpha in human hepatocellular carcinoma. Liver 13: $151-155$

El-Serag HB, Mason AC (1999) Rising incidence of hepatocellular carcinoma in the United States. $N$ Engl J Med 340: $745-750$

Hamada K, Shinomiya H, Asano Y (2001) Molecular cloning of human squamous cell carcinoma antigen 1 gene and characterization of its promoter. Biochem Biophys Acta 1518: $124-131$

Huntington JA, Read RJ, Carrell RW (2000) Structure of a serpin-protease complex shows inhibition by deformation. Nature 407: $923-926$

Kato H (1996) Expression and function of squamous cell carcinoma antigen. Anticancer Res 16: 2149-2154

Naka T, Toyota N, Kaneko T, Kaibara N (1998) Protein expression of $\mathrm{p} 53, \mathrm{p} 21 \mathrm{WAF} 1$, and $\mathrm{Rb}$ as prognostic indicators in patients with surgically treated hepatocellular carcinoma. Anticancer Res 18: $555-564$

Sakaguchi Y, Kishi F, Murakami A, Suminami Y, Kato H (1999) Structural analysis of human SCC antigen 2 promoter. Biochem Biophys Acta 1444: $111-116$

Schneider SS, Schick KE, Fish E, Miller JC, Pena DS, Treter SM, Hui GA, Silverman A (1995) A serine proteinase inhibitor locus at 18q21.3 
contains a tandem duplication of the human squamous cell carcinoma antigen gene. Proc Natl Acad Sci USA 92: 3147-3151

Shirota Y, Kaneko S, Honda M, Kawai H, Kobayashi K (2001) Identification of differentially expressed genes in hepatocellular carcinoma with cDNA microarrays. Hepatology 33: $832-840$

Suminami Y, Kishi K, Sekiguchi K, Kato H (1991) Squamous cell carcinoma antigen is a new member of the serine protease inhibitors. Biochem Biophys Res Commun 181: $51-58$

Suminami Y, Nagashima S, Vujanovic NL, Hirabayashi K, Kato H, Whiteside TL (2000) Inhibition of apoptosis in human tumour cells by the tumour-associated serpin, SCC antigen. Br J Cancer 82: 981 - 989

Suminami Y, Shigeki N, Murakami A, Nawata S, Gondo T, Hirakawa H, Numa F, Silverman GA, Kato H (2001) Suppression of a squamous cell carcinoma (SCC)-related serpin, SCC antigen, inhibits tumor growth with increased intratumoral infiltration of killer cells. Cancer Res 61: $176-180$

Takeo S, Arai H, Kusano N, Harada T, Furuya T, Kawauchi S, Oga A, Hirano T, Yoshida T, Okita K, Sasaki KI (2001) Examination of oncogene amplification by genomic DNA microarray in hepatocellular carcinomas. Comparison with comparative genomic hybridization analysis. Cancer Genet Cytogenet 130: 127-132

Xu XR, Huang J, Xu ZG, Qian BZ, Zhu ZD, Yn Q, Cai T, Zhang X, Xiao HS, Liu F, Huang QH, Chen ZH, Du JJ, Hu W, Shen KT, Lu G, Fu G, Zhong M, $\mathrm{Xu} \mathrm{SH}, \mathrm{Gu}$ WY, Huang W, Zhao XT, Hu GX, Gu JR (2001) Insight into hepatocellular carcinogenesis at transcriptome level by comparing gene expression profiles of hepatocellular carcinoma with those of corresponding noncancerous liver. Proc Natl Acad Sci USA 98: $15089-15094$ 